Original article

\title{
Depression and anxiety in Malaysian population during third wave of the COVID-19 pandemic
}

\author{
Roy Rillera Marzo ${ }^{\mathrm{a}, \mathrm{b}}$, Vineet Vinay ${ }^{\mathrm{c}}$, Rafidah Bahari ${ }^{\mathrm{d}}$, Shekhar Chauhan ${ }^{\mathrm{e}, *}$, \\ Deborah Anak Fo Ming ${ }^{\mathrm{b}}$, Stephanie Fernandez A/P. Nelson Fernandez ${ }^{\mathrm{b}}$, \\ Colin Cornelius Pereira Johnson ${ }^{\mathrm{b}}$, Agkesh Qumar A/L Thivakaran ${ }^{\mathrm{b}}$, \\ Mohammad Meshbahur Rahman ${ }^{\mathrm{f}}$, Sonu Goel ${ }^{\mathrm{g}}$ \\ a Department of Community Medicine, International Medical School, Management and Science University, Selangor, 40100, Malaysia \\ ${ }^{\mathrm{b}}$ Department of Community Medicine, Faculty of Medicine, Asia Metropolitan University, Johor Bahru, 81750, Malaysia \\ ${ }^{c}$ Department of Public Health Dentistry, Sinhgad Dental College and Hospital, Pune, Maharashtra, India \\ ${ }^{\mathrm{d}}$ Department of Psychiatry, Faculty of Medicine, University of Cyberjaya, Malaysia \\ ${ }^{\mathrm{e}}$ International Institute for Population Sciences, Mumbai, India \\ ${ }^{\mathrm{f}}$ Biomedical Research Foundation (BRF), Dhaka, Bangladesh \\ ${ }^{\mathrm{g}}$ School of Medicine, University of Limerick, Ireland
}

\section{A R T I C L E I N F O}

\section{Keywords:}

Depression

Anxiety

Coronavirus

Patient health questionnaires

Zung's self-rating anxiety scale

\begin{abstract}
A B S T R A C T
Introduction: The outbreak of coronavirus posits deleterious consequences on global healthcare system while affecting human life in every aspect. Despite several measures undertaken to limit the socio-economic effect of coronavirus, various challenges remain pervasive, and one such challenge is mental health, particularly depression and anxiety. Therefore, this study examines the prevalence and determinants of depression and anxiety in Malaysian population during third wave of COVID-19.

Methods: A cross-sectional online survey was carried out via social media platforms and 1544 Malaysians were selected. The level of depression was assessed by Patient Health Questionnaires (PHQ-9) and scored accordingly for categorization. Zung's Self-Rating Anxiety Scale (SAS) was used as a self-assessment survey to quantify the level of anxiety of persons experiencing anxiety-related symptoms. Percentage distribution and logistic regression analysis were used in the data analysis.

Results: Results showed that one-fourth (25.1\%) of the participants had severe depressive symptoms. Almost onesixth $(18.7 \%)$ had mild depressive symptoms and one-third $(34.1 \%)$ had mild to moderate anxiety symptoms. Age, gender, and friends infected with virus were the three important predictors of depression and anxiety. The odds of having depression (OR $=1.44$; C.I. $=1.32-1.62)$ and anxiety $(\mathrm{OR}=1.36$; C.I. $=1.27-1.47)$ were significantly higher among females than in males.

Conclusion: A significant proportion of the study participants were facing mild to severe depression and anxiety symptoms which is very alarming as the pandemic is still now increasing across the country. Immediate interventions including community counselling programmes, TV and social media campaigns are urgently needed to reduce the psychological stress among the Malaysian population.
\end{abstract}

Funding

This research did not receive any specific grant from funding agencies in the public, commercial, or not-for-profit sectors.
The manuscript has been read and approved by all the authors. Each author believes that the work in the manuscript represents honest work. This article is not simultaneously submitted to any other journal for review and/or publication and has not been published anywhere in full

\footnotetext{
* Corresponding author.

E-mail addresses: rrmtexas@yahoo.com (R.R. Marzo),dr_vineet_vinay@hotmail.com (V.Vinay), rafidahbahari@cyberjaya.edu.my (R. Bahari), shekhariips2486@ gmail.com (S. Chauhan), deborahfoming98@gmail.com (D.A.F. Ming), stephaniefz2002@gmail.com (S.F.A/P. Nelson Fernandez), colinccpj@gmail.com (C.C.P. Johnson), flashagkesh@gmail.com (A.Q.A. Thivakaran), meshbah037@gmail.com (M.M. Rahman), sonugoel007@yahoo.co.in (S. Goel).
} 


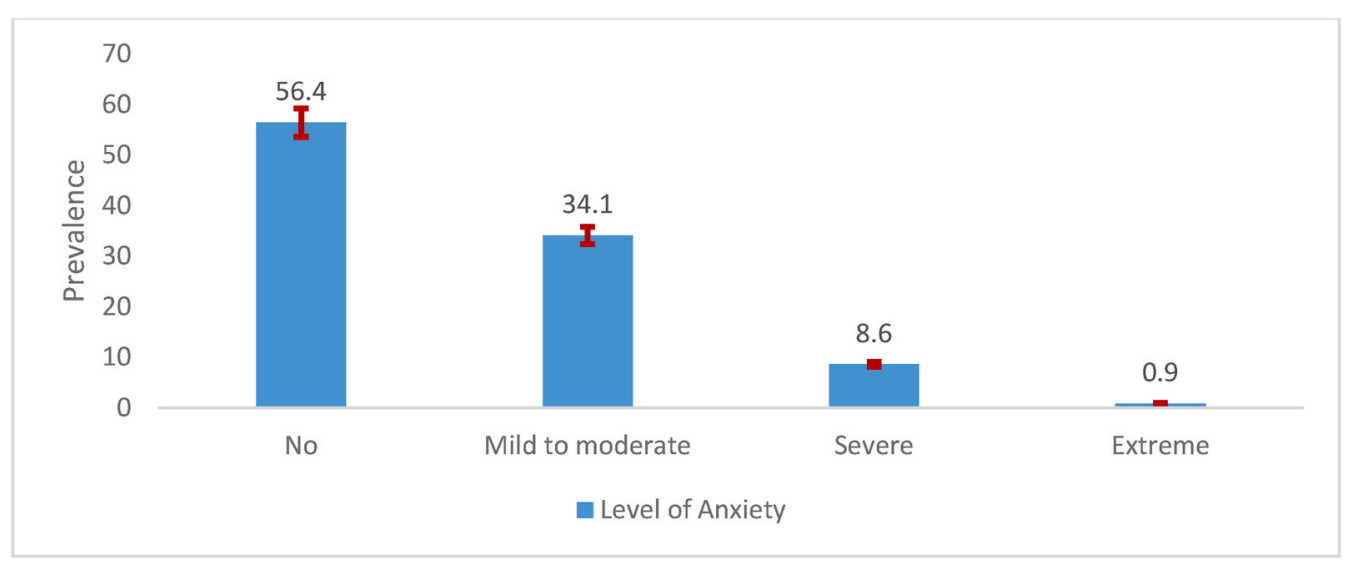

Fig. 1. Prevalence of different levels of anxiety during third wave of COVID-19 in Malaysia.

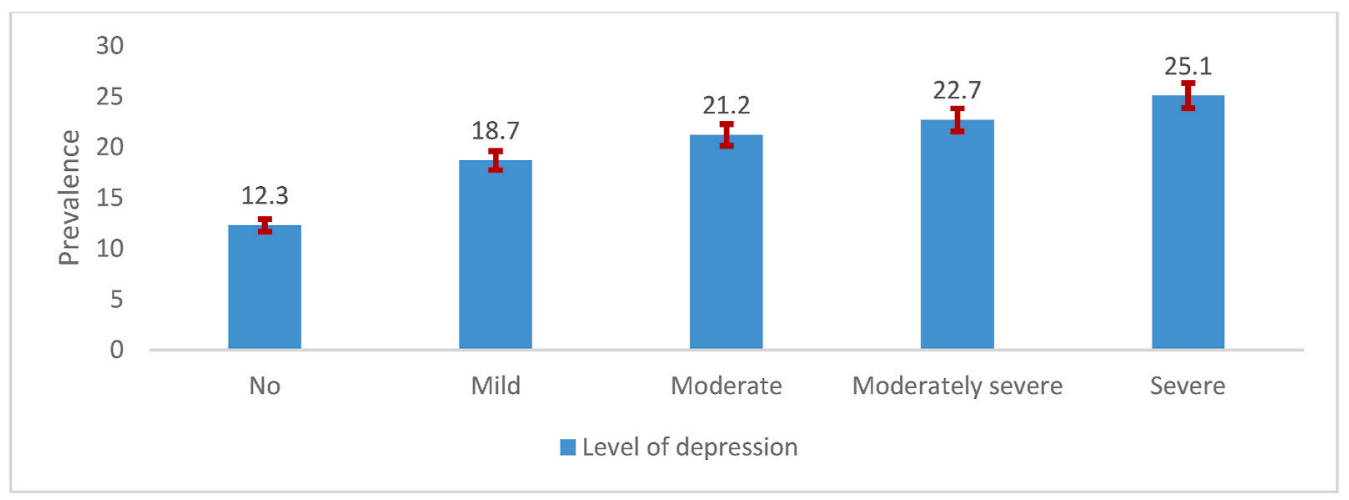

Fig. 2. Prevalence of the levels of depression during third wave of COVID-19 in Malaysia.

or in parts.

\section{Introduction}

The COVID-19 pandemic has made huge global impacts, including high mortality and morbidity rates, loss of income, and sustained social isolation for billions of people. ${ }^{1}$ The effect this crisis will have on the mental health of the population is unknown, both in the short and long term. There is minimal evidence about the acute phase mental health impacts of large-scale epidemics across communities. Existing work has focused on those individuals directly affected by the disease. ${ }^{1}$ The COVID-19 epidemic had a gripping impact not only on health workers, ${ }^{2,3}$ but also over general population. ${ }^{4-6}$

A few studies from different settings investigated the role of various socio-demographic and COVID-19 related factors for mental health. ${ }^{7-11}$ Their findings suggest that women, younger people, people with chronic conditions are at severe risk of reporting mental health problems during COVID-19. In October 2020, Malaysia has entered into the third wave of COVID-19 Pandemic. ${ }^{12}$ Malaysia, like many other countries, relied on a lockdown strategy to curb down the menace of COVID-19. ${ }^{13}$ This was to ensure social distancing through home quarantine to help curb the spread of the virus among its population. However, a few studies noted an elevated risk of depression during quarantine as a result of COVID-19 pandemic. ${ }^{11,14}$ There are clear reasons to expect that these government policies and physical distancing measures aimed at limiting disease spread will impact the mental health of the community. For instance, loss of employment, financial strain, and social isolation are all well-documented correlates of mental health problems. In many countries, these measures have already resulted in an enormous increase in unemployment, likely causing significant financial strain for many. ${ }^{15}$

Mental health disorders are a tremendous public health concern throughout the world. The recent third wave of COVID-19 pandemic in Malaysia had caused anxiety and fear toward the virus due to the complex pathogenicity of the virus and its constantly mutating nature. There is an inadequate attention paid to the understanding and studying the associated factors and prevalence of depression and anxiety during the third wave of the COVID-19 pandemic in Malaysia. Most of the recent studies done in Malaysia are studies conducted on university students and the study period was during the initial stage of the pandemic. ${ }^{16,17}$ The lack of knowledge implies that Malaysia cannot fully aid and support her citizen as they encounter the unprecedented COVID-19 pandemic. This study is the first to correlate depression and anxiety during the third wave of the COVID-19 pandemic in Malaysia. An online cross-sectional multi-country study has failed to link mental health and COVID-19 pandemic relation. ${ }^{18}$ Therefore, there is a need to explore possible association between COVID-19 and mental health. This study intends to examine depression and anxiety during third wave of COVID-19 in Malaysian population.

\section{Methods}

\subsection{Study setting and population}

The study was conducted following the protocol and approved by the Ethics Committee of Asia Metropolitan University (Project ID Number: AMU/MREC/FOM/NF/09/2020). Furthermore, a consent was taken from the respondents too. An internet-based cross-sectional survey was conducted from January 15, 2021, to April 15, 2021, during the movement restriction took place, and the number of cases and deaths from COVID-19 was increasing in Malaysia. The snowball sampling method was used for the data collection using research networks of universities, hospitals, friends, and their relatives. The survey was 
Table 1

Socio-demographic and economic profiles of the respondents.

\begin{tabular}{|c|c|c|}
\hline Variables & Frequency & Percent \\
\hline \multicolumn{3}{|l|}{ Gender } \\
\hline Male & 402 & 25.9 \\
\hline Female & 1152 & 74.1 \\
\hline \multicolumn{3}{|l|}{ Age } \\
\hline 15 to $<17$ years & 47 & 3.0 \\
\hline $17-20$ years & 321 & 20.7 \\
\hline $21-24$ years & 675 & 43.4 \\
\hline$>24$ years & 511 & 32.9 \\
\hline \multicolumn{3}{|l|}{ Residency } \\
\hline Urban (town/city) & 1318 & 84.8 \\
\hline Rural (countryside) & 236 & 15.2 \\
\hline \multicolumn{3}{|l|}{ Race } \\
\hline Malay & 887 & 57.1 \\
\hline Chinese & 186 & 12.0 \\
\hline Indian & 384 & 24.7 \\
\hline Others & 97 & 6.2 \\
\hline \multicolumn{3}{|l|}{ Marital status } \\
\hline Married & 177 & 11.4 \\
\hline Single & 1328 & 85.5 \\
\hline Divorced & 12 & 0.8 \\
\hline Widowed & 37 & 2.4 \\
\hline \multicolumn{3}{|l|}{ Occupational status } \\
\hline Full-time & 450 & 29.0 \\
\hline Part-time & 58 & 3.7 \\
\hline Unemployed/Homemaker & 122 & 7.9 \\
\hline Student & 924 & 59.5 \\
\hline \multicolumn{3}{|l|}{ Family income } \\
\hline Less than RM 4,849 & 825 & 53.1 \\
\hline Between RM 4,849 - RM 10,959 & 512 & 32.9 \\
\hline More than RM 10,960 & 217 & 14.0 \\
\hline \multicolumn{3}{|l|}{ Educational status } \\
\hline No formal education & 8 & 0.5 \\
\hline Primary & 10 & 0.6 \\
\hline Secondary & 176 & 11.3 \\
\hline Post-secondary education & 445 & 28.6 \\
\hline Tertiary & 915 & 58.9 \\
\hline \multicolumn{3}{|l|}{ Anxiety responses } \\
\hline Normal & 876 & 56.4 \\
\hline mild to moderate & 530 & 34.1 \\
\hline Severe & 134 & 8.6 \\
\hline most extreme & 14 & 0.9 \\
\hline \multicolumn{3}{|l|}{ Depression responses } \\
\hline None & 192 & 12.4 \\
\hline Mild & 290 & 18.7 \\
\hline Moderate & 330 & 21.2 \\
\hline moderately severe & 352 & 22.7 \\
\hline Severe & 390 & 25.1 \\
\hline
\end{tabular}

piloted on a sample of 50 to test its validity. The data from the pilot survey were not included in the final analysis. All participants were informed about the survey's purpose and provided their informed consent before starting. A total of 1554 respondents completed the survey.

The google doc link was sent through WhatsApp, Facebook, emails, and various social media platforms to the contacts of the authors, and participants were requested to roll out the online questionnaire to as many people and this way, the study adopted the snowball sampling technique. In order to obtain a good number of responses in the online survey, snowball sampling has been used, and this technique has been widely used in literature. In Malaysia, the working age started at 15 years and the respondent aged 15 years or more were included in the study. The participant was only permitted to respond once by setting the feature that prevents more than one response. The google form was set up for anonymous responses without identifying their emails or contacts.

\subsection{Study measurement}

Patient Health Questionnaires (PHQ-9) is a widely used instrument to measure and screen the overall presence and level of depression and is an easy tool to be used in a survey. ${ }^{19}$ It comprises nine questions, and participants were asked to select a score on each question from the survey, which scores as " 0 " for "not at all" to " 3 " for "nearly every day." The scores are categorized into different categories whereby score (5-9) is deemed to have minimal symptoms. Meanwhile, score (10-14) is mild depression, and score (15-19) is moderately severe depression. For score $(>20)$ is said to be severe depression. Participants were asked to select a score on each question from the survey.

In addition, Zung's Self-Rating Anxiety Scale (SAS) is a selfassessment survey to quantify the level of anxiety for patients experiencing anxiety-related symptoms. ${ }^{20,21}$ There are fifteen questions worded toward increasing anxiety levels and five questions worded toward decreasing anxiety levels. Participants were asked to elaborate on each response. Each question is scored on a scale of 1-4 (none or a little of the time, some of the time, good part of the time, most of the time). The scores were ranged from 20 to 80 , where the normal range is between 20 and 44 , mild to moderate anxiety levels is from 45 to 59$)$ and (60-74) is marked to severe anxiety levels, and extreme anxiety levels is from (75-80).

\subsection{Validity \& reliability}

The diagnostic validity of the PHQ-9 was shown in studies involving multiple primary care and obstetrical clinics. PHQ-9 has a sensitivity of 0.80 and a specificity of 0.92 for major depressive disorder. ${ }^{22}$ Research conducted in 2019 had shown that the Cronbach alpha of PHQ-9 has a great satisfactory result of 0.87 and convergent validity with the BDI-II scale [Pearson's correlation of $0.88,(\mathrm{p}<0.01)] .{ }^{23}$ This tool has also been shown to be reliable in COVID-19 related studies various studies have used this tool before. ${ }^{24,25}$

Meanwhile, Zung's Self-Rating Anxiety Scale (SAS) has also proven reliable and valid to assess the scale of the most common general anxiety disorders. In a recent study, Zung's SAS has demonstrated good psychometric properties (Cronbach's alpha of 0.897 and intraclass correlation of 0.913). ${ }^{26}$ This tool also has been used in previous COVID-19 related studies. ${ }^{17}$

\subsection{Data analysis}

The data obtained was entered in an excel sheet, and responses were coded appropriately. Statistical analysis was performed using SPSS (Statistical Package for the Social Sciences) (v.21). Descriptive statistics were performed for demographic details along with depression and anxiety scores. Depression and anxiety scores were classified on a 4 point Likert scale. The chi-square test of proportion was performed to analyze the demographic details further. Binary logistic regression was performed for selected variables with predictors of depression and anxiety. Binary logistic regression was used to identify variables influencing depression and anxiety among students by categorizing the outcome variable into two categories, i.e., depressed = 'yes' and 'no' and anxious = 'yes' and 'no,' which would provide a clearer idea about how intensely different factors are influencing the outcomes. The results were interpreted and depicted appropriately in tables with $95 \% \mathrm{CI}$ and $\mathrm{p}$ $<0.05$, considered to be significant.

\section{Results}

Fig. 1 depicts the percentage of Malaysians by level of anxiety during the third wave of COVID-19 in Malaysia. Results noticed that more than half of the surveyed respondents (56.4\%) did not report anxiety. Around one-third $(34.1 \%)$ of the respondents reported mild to moderate anxiety and almost $9 \%$ reported severe anxiety. 
Table 2

Depression and anxiety levels according to respondent's socio-demographic and economic profile $(\mathrm{n}=1554)$.

\begin{tabular}{|c|c|c|c|c|c|c|c|c|c|}
\hline \multirow[t]{2}{*}{ Variable } & \multicolumn{5}{|l|}{ Depression } & \multicolumn{4}{|l|}{ Anxiety } \\
\hline & None & Mild & Moderate & Moderately-severe & Severe & Normal & Mild to moderate & Severe & Extreme \\
\hline \multicolumn{10}{|l|}{ Gender } \\
\hline Male & $80(19.9)$ & $97(24.1)$ & $88(21.9)$ & $87(21.6)$ & $50(12.4)$ & 293(72.9) & $76(18.9)$ & $30(7.5)$ & $3(0.7)$ \\
\hline Female & $112(9.7)$ & $193(16.8)$ & $242(21)$ & $265(23)$ & $340(29.5)$ & $583(50.6)$ & $454(39.4)$ & $104(9.0)$ & $11(1.0)$ \\
\hline \multicolumn{10}{|l|}{ Residency } \\
\hline Urban (town/city) & $168(12.7)$ & $234(17.8)$ & $289(21.9)$ & - & - & $746(56.6)$ & $444(33.7)$ & $117(8.9)$ & - \\
\hline Rural (countryside) & $24(10.2)$ & $56(23.7)$ & $41(17.4)$ & - & - & $130(55.1)$ & $86(36.4)$ & $17(7.2)$ & - \\
\hline \multicolumn{10}{|l|}{ Race } \\
\hline Malay & $64(7.2)$ & $144(16.2)$ & $182(20.5)$ & $227(25.6)$ & $270(30.4)$ & 435(49) & $350(39.5)$ & $93(10.5)$ & $9(1)$ \\
\hline Chinese & $31(16.7)$ & $48(25.8)$ & $55(29.6)$ & $38(20.4)$ & $14(7.5)$ & $128(68.8)$ & $48(25.8)$ & $8(4.3)$ & $2(1.1)$ \\
\hline Indian & $85(22.1)$ & $78(20.3)$ & $77(20.1)$ & $66(17.2)$ & $78(20.3)$ & $261(68)$ & $95(24.7)$ & $25(6.5)$ & $3(0.8)$ \\
\hline Others & $12(12.4)$ & $20(20.6)$ & $16(16.5)$ & $21(21.6)$ & $28(28.9)$ & $52(53.6)$ & $37(38.1)$ & $8(8.2)$ & $0(0)$ \\
\hline \multicolumn{10}{|l|}{ Marital status } \\
\hline Married & $43(24.3)$ & $58(32.8)$ & $35(19.8)$ & $18(10.2)$ & 23(13) & $122(68.9)$ & $38(21.5)$ & $17(9.6)$ & $0(0)$ \\
\hline Single & $142(10.7)$ & $224(16.9)$ & $290(21.8)$ & $320(24.1)$ & $352(26.5)$ & $732(55.1)$ & $471(35.5)$ & $111(8.4)$ & $14(1.1)$ \\
\hline Divorced & $3(25)$ & $4(33.3)$ & $2(16.7)$ & $2(16.7)$ & $1(8.3)$ & $8(66.7)$ & $4(33.3)$ & $0(0)$ & $0(0)$ \\
\hline Widowed & $4(10.8)$ & $4(10.8)$ & $3(8.1)$ & $12(32.4)$ & $14(37.8)$ & $14(37.8)$ & $17(45.9)$ & $6(16.2)$ & $0(0)$ \\
\hline \multicolumn{10}{|l|}{ Occupational status } \\
\hline Full-time & $71(15.8)$ & $117(26)$ & $92(20.4)$ & $81(18)$ & $89(19.8)$ & $269(59.8)$ & $151(33.6)$ & $28(6.2)$ & $2(0.4)$ \\
\hline Part-time & $7(12.1)$ & $10(17.2)$ & $16(27.6)$ & $11(19)$ & $14(24.1)$ & $33(56.9)$ & $18(31)$ & $7(12.1)$ & $0(0)$ \\
\hline Unemployed/Homemaker & $11(9)$ & $20(16.4)$ & $20(16.4)$ & $29(23.8)$ & $42(34.4)$ & $66(54.1)$ & $41(33.6)$ & $14(11.5)$ & $1(0.8)$ \\
\hline Student & $103(11.1)$ & $143(15.5)$ & $202(21.9)$ & $231(25)$ & $245(26.5)$ & $508(55)$ & $320(34.6)$ & $85(9.2)$ & $11(1.2)$ \\
\hline \multicolumn{10}{|l|}{ Family income } \\
\hline Less than RM 4,849 & $77(9.3)$ & $141(17.1)$ & $179(21.7)$ & $191(23.2)$ & $237(28.7)$ & $437(53)$ & $297(36)$ & $81(9.8)$ & $10(1.2)$ \\
\hline Between RM 4,849 - RM 10,959 & $68(13.3)$ & $115(22.5)$ & $97(18.9)$ & $121(23.6)$ & $111(21.7)$ & $303(59.2)$ & $170(33.2)$ & $36(7)$ & $3(0.6)$ \\
\hline More than RM 10,960 & $47(21.7)$ & $34(15.7)$ & $54(24.9)$ & $40(18.4)$ & $42(19.4)$ & $136(62.7)$ & $63(29)$ & $17(7.8)$ & $1(0.5)$ \\
\hline \multicolumn{10}{|l|}{ Educational Status } \\
\hline No formal education & $0(0)$ & $2(25)$ & $0(0)$ & $2(25)$ & $4(50)$ & $1(12.5)$ & $6(75)$ & $1(12.5)$ & $0(0)$ \\
\hline Primary & $0(0)$ & $1(10)$ & $1(10)$ & $4(40)$ & $4(40)$ & $2(20)$ & $4(40)$ & $4(40)$ & $0(0)$ \\
\hline Secondary & $15(8.5)$ & $30(17)$ & $31(17.6)$ & $50(28.4)$ & $50(28.4)$ & $89(50.6)$ & $68(38.6)$ & $18(10.2)$ & $1(0.6)$ \\
\hline Post-secondary education & 47(106.) & $75(16.9)$ & $94(21.1)$ & $91(20.4)$ & $138(31)$ & $232(52.1)$ & $163(36.6)$ & $45(10.1)$ & $5(1.1)$ \\
\hline Higher education & $130(14.2)$ & $182(19.9)$ & $204(22.3)$ & $205(22.4)$ & $194(22.4)$ & $552(60.3)$ & $289(31.6)$ & $66(7.2)$ & $8(0.9)$ \\
\hline
\end{tabular}

Fig. 2 depicts the percentage of respondents by level of depression during the third wave of COVID-19 in Malaysia. Results found that almost one-fourth $(25.1 \%)$ of the respondents reported severe depression and more than one-fifth $(22.7 \%)$ reported moderately severe depression during the third wave of COVID-19 in Malaysia.

The demographic profile was recorded for all the participants, including various variables like gender, age, residency, race, marital status, occupational status, family income, and educational status. The details of responses were recorded and analyzed as presented in Table 1. The overall depression and anxiety scores were also calculated for the sample and categorized based on severity (Table 1).

Table 1 shows the descriptive information of different selected variables of the surveyed Malaysian population during third wave of COVID-19 pandemic. Results show that 390 (25.1\%) individuals were found to have severe depressive symptoms while 290 (18.7\%) had mild depressive symptoms, and $14(0.9 \%)$ individuals were found to have severe anxiety symptoms while $530(34.1 \%)$ had mild to moderate symptoms (Graph $1 \& 2$ ). More than $70 \%$ of the individuals were females (74.1\%), and the rest were males. Majority of the individuals lived in urban areas $1318(84.8 \%)$. More than a half of the individuals were Malay $887(57.1 \%)$ and over half of individuals were students 924 (59.5\%)

Table 2 shows the prevalence of depression and anxiety among Malaysian individuals. Females (29.5\%) had higher severe depressive symptoms than the male (12.4\%) counterparts, whereas students (26.5\%) showed higher depressive symptoms than other occupation groups. Depression was also prevalent among single individuals (26.5\%) than married or divorced individuals. Besides, individuals living with in urban areas (21.9\%) showed moderate depressive symptoms. In the case of anxiety, 454(87.7\%) females exhibited mild to moderate anxiety symptoms. Out of the total participants, 320 (34.6) students suffering from an anxiety disorder, also tertiary education 289 (31.6\%) showed mild to moderate anxiety. Like depression, anxiety was also prevalent mostly among single individuals 471 (35.5\%). Moreover, individuals living in urban areas (33.7\%) also showed symptoms of anxiety.

We applied inferential statistics to establish the association between the different variables/items of questionnaires that we recorded. Binary logistic regression was applied, and OR (odds ratio) was calculated to analyze the risk of anxiety and depression with the independent variables. Individuals above 17 years of age had more depression and anxiety symptoms than underage participants. Females had 1.4 (95\% CI: $1.318-1.620 ; 1.273-1.468$ ) times more likely to be depressed or anxious than those with no such worries. Students living with families were 2.6 times (95\% CI: $1.418,4.751$ ), more likely to be depressed than the students living apart from families. At the same time, residency did not have any effect on anxiety or depression. On the other hand, individuals whose family income was affected by the pandemic were 0.6 times $(95 \%$ CI: 0.441-0.844), more likely to show depression symptoms than their counterparts with no such involvement. Individuals who had privacy at home were 1.717 times likely to exhibit depression, and those who exercise were approx. 1.480 times more likely to exhibit depression and 1.640 times more likely to exhibit anxiety symptoms. Respondents who were victims of abuse were 0.2 times (95\% CI: 1.021, 3.308), more likely to have depression and anxiety symptoms. Participants whose friends were infected with the virus were 1.486 times more likely to be depressed and 1.597 more likely to be anxious than the participant whose friends are not infected (Table 3).

\section{Discussion}

This large-scale study confirmed that a significant proportion of the surveyed Malaysian population suffered from deterioration of mental 
Table 3

Summary of the Binary logistic regression model for predicting depressive and anxiety symptoms.

\begin{tabular}{|c|c|c|c|c|}
\hline \multirow[t]{2}{*}{ Variables } & \multicolumn{2}{|l|}{ Depression } & \multicolumn{2}{|l|}{ Anxiety } \\
\hline & OR(95\% CI) & $\begin{array}{l}\mathrm{P}- \\
\text { value }\end{array}$ & OR(95\% CI) & $\begin{array}{l}\mathrm{P} \text { - } \\
\text { value }\end{array}$ \\
\hline \multicolumn{5}{|l|}{ Age } \\
\hline \multicolumn{5}{|l|}{15 to $<17$ years $($ Ref) } \\
\hline $17-20$ years & $\begin{array}{l}4.49 \\
(1.04-19.31)\end{array}$ & .044 & $\begin{array}{l}1.97 \\
(1.04-3.74)\end{array}$ & 0.03 \\
\hline 21-24 years & $\begin{array}{l}2.84 \\
(1.69-4.76)\end{array}$ & .000 & $\begin{array}{l}1.67 \\
(1.23-2.26)\end{array}$ & 0.001 \\
\hline$>24$ years & $\begin{array}{l}1.72 \\
(1.22-2.42)\end{array}$ & .002 & $\begin{array}{l}1.21 \\
(0.94-1.55)\end{array}$ & 0.145 \\
\hline \multicolumn{4}{|l|}{ Gender } & \\
\hline Female & $\begin{array}{l}1.44 \\
(1.32-1.62)\end{array}$ & .000 & $\begin{array}{l}1.36 \\
(1.27-1.47)\end{array}$ & 0.000 \\
\hline \multicolumn{5}{|l|}{ Residency } \\
\hline Rural (countryside) & $\begin{array}{l}0.83 \\
(.52-1.33)\end{array}$ & .438 & $\begin{array}{l}0.98 \\
(0.73-1.32)\end{array}$ & 0.916 \\
\hline $\begin{array}{l}\text { Family's source of } \\
\text { income affected }\end{array}$ & $0.61(.44-.84)$ & .003 & $\begin{array}{l}0.82 \\
(0.66-1.02)\end{array}$ & 0.080 \\
\hline New hobby & $\begin{array}{l}1.38 \\
(.96-1.97)\end{array}$ & .082 & $\begin{array}{l}0.99 \\
(0.79-1.25)\end{array}$ & 0.974 \\
\hline Privacy in home & $\begin{array}{l}1.72 \\
(1.17-2.51)\end{array}$ & .005 & $\begin{array}{l}1.59 \\
(1.26-1.99)\end{array}$ & 0.000 \\
\hline Performing exercise & $\begin{array}{l}1.48 \\
(1.04-2.11)\end{array}$ & .030 & $\begin{array}{l}1.64 \\
(1.31-2.05)\end{array}$ & 0.000 \\
\hline Victim of abuse & $0.25(.09-.73)$ & .011 & $\begin{array}{l}0.29 \\
(0.18-.44)\end{array}$ & 0.000 \\
\hline $\begin{array}{l}\text { Currently infected with } \\
\text { virus }\end{array}$ & $\begin{array}{l}1.67 \\
(.62-4.53)\end{array}$ & .312 & $\begin{array}{l}0.95 \\
(0.48-1.90)\end{array}$ & 0.895 \\
\hline $\begin{array}{l}\text { Infected with virus in the } \\
\text { past }\end{array}$ & $\begin{array}{l}0.21 \\
(.03-1.72)\end{array}$ & .147 & $\begin{array}{l}0.80 \\
(0.37-1.72)\end{array}$ & 0.569 \\
\hline $\begin{array}{l}\text { Family member infected/ } \\
\text { affected with virus }\end{array}$ & $\begin{array}{l}0.83 \\
(.46-1.49)\end{array}$ & .532 & $\begin{array}{l}0.97 \\
(0.69-1.36)\end{array}$ & 0.865 \\
\hline $\begin{array}{l}\text { Friends infected with } \\
\text { virus }\end{array}$ & $\begin{array}{l}1.48 \\
(1.34-1.69)\end{array}$ & .000 & $\begin{array}{l}1.59 \\
(1.47-1.75)\end{array}$ & 0.000 \\
\hline
\end{tabular}

health when the number of cases surged rapidly even a year after the COVID-19 pandemic began. During this third wave of the pandemic, it was found that $70 \%$ of the respondents suffered from moderate to severe depression and $43.5 \%$ mild to severe anxiety. A systematic review reported that the rates of depression during the first wave of the pandemic be between 14.6 and $48.3 \%$ and rates of anxiety to be between 6.33 and $50.9 \% .{ }^{27}$ There seems to be an increasing trend for anxiety and depression with time, which was also seen in another study. ${ }^{28}$ In that study, it was found that after five months from the start of the pandemic, the rates of depression and anxiety increased, while the rate of distress reduced. One of the lessons learned from previous pandemics is that even when an outbreak settles, the effect on mental health does not immediately end. ${ }^{29}$ At the moment, there is no end in sight for the COVID-19 pandemic, which may be a reason why the rates of anxiety and depression have continued to rise.

Previous studies have implicated that being young, female, single, and student increases the risk for developing anxiety and depression during an outbreak. ${ }^{27}$ The strongest predictor for anxiety and depression is the female gender. ${ }^{14,30-32}$ This is hardly surprising since it has been long established that both conditions affect more females than males. The other expected predictor is having friends whom the COVID-19 had infected since it drives home the reality of the situation. This was also demonstrated in studies from previous outbreaks, such as the 2003 SARS pandemic in Beijing. ${ }^{33}$

While working from home is a welcome relief for most people, there is an unexpected drawback. It has been found that during this period, there had been an increase in domestic violence cases. ${ }^{34,35}$ There are many reasons for this phenomenon, but two are more prominent than others. Firstly, the mass quarantine orders or "lockdown" forces couples and families to be in constant company with each other, which positively improves relationships. However, those with turbulent and abusive relationships, being in close contact for a prolonged period, allowed for many opportunities for violence. ${ }^{36}$ Furthermore, the lockdown enforced in many countries had a significant negative impact on the economy. As a result, many people lost their jobs or had significantly reduced income. This stress added fuel to the fire and resulted in more domestic violence cases. ${ }^{37}$ In turn, victims of abuse, who had no means of escape due to lockdown, develop anxiety and depression, as seen in our study. The rise in domestic violence, many have argued, is another hidden epidemic caused by the measures to control the COVID-19 epidemic. $^{38}$

Paradoxically, this study found that regular exercise is a predictor for the development of anxiety and depression. This seems to be contrary to published research. Published data in the form of systematic reviews have found that physical exercise does reduce symptoms of anxiety and depression. ${ }^{39,40}$ However, upon further examination, it is revealed that those systematic reviews also included studies with significant methodological issues, which prevented a robust conclusion from being made. The very nature of the exercise, which is highly heterogeneous, prevents the appropriate conclusion from being made. Also, the main motivating factor for exercising seems for weight loss, while stress and low mood can both enable and prevent people from exercising. ${ }^{41}$ Hence, perhaps participants in our study exercise to manage their weight issues, and it is this problem with the weight that predisposes them to low mood and anxiety. Previous studies have indeed found that the increase in body weight raises the risk of developing anxiety and depression, especially among young women. ${ }^{42}$ All in all, it is probably reasonable to conclude. However, there is a lack of robust evidence that physical activity protects against anxiety and depression; it may still be beneficial, primarily when used together with medication of psychotherapy. ${ }^{43}$

On the other hand, our study also found that having family income affected by the pandemic is a predictor for depression, but not anxiety. The association between income and mental health has been well documented. ${ }^{44}$ It has also been reported that the mass quarantine, a measure to control the outbreak's spread, causes reduction or loss of income. ${ }^{45}$ However, this study found that loss of income is a predictor for depression rather than anxiety. Perhaps it is the nature of this pandemic, which is prolonged with no end in sight that causes depression to take over. Also, more importantly, the temporal association between this study and the third wave of the COVID-19 pandemic. The recent surge in the number of cases prior to the research may trigger a depressive episode in the participants.

The final intriguing predictor for depression found in this study has privacy at home. There is a lack of research to support this finding. However, self-isolation is a symptom of depression. It could be that having privacy means that they are allowed to self-isolate, and it is depression that predicts self-isolation, not the other way around. Nevertheless, more research needs to be done to understand this phenomenon.

\section{Limitations of the study}

The distribution of the survey through online platforms introduced a recruitment bias in which only those with access to electronic devices and the internet could participate. Using cross-sectional design can only determine the association and not causation and effect. We did not assess participants' psychological conditions before the pandemic and could not rule out pre-existing anxiety or depression in our participants. Furthermore, we did not also gather data from different pandemic stages, and hence comparisons cannot be made. All these factors limit the conclusion and applicability of the study.

\section{Conclusion}

Even a year on, especially following surges of cases of COVID-19, 
anxiety, and depression are more prevalent than ever. During the third wave of the pandemic, almost three-quarter of participants suffered from depression, and about half of them suffered from anxiety. Predictors of anxiety and depression were included female respondents, young, single, student, domestic violence, and person who maintain regular exercise. Immediate interventions including community counselling programmes, institutional campaigns, awareness through TV and social media can be implemented to reduce the severity of depression and anxiety. It is recommended to bring forth psychiatric and psychological support; specifically, to the female gender.

\section{Funding}

The authors received no specific funding for this work.

\section{CRediT authorship contribution statement}

Roy Rillera Marzo: Conceptualization, data collection, Methodology, Software, Validation, Formal analysis, Investigation, Resources, Visualization, Supervision, Writing - review \& editing, Writing - original draft. Vineet Vinay: Formal analysis, Investigation, Validation. Rafidah Bahari: Formal analysis, Investigation, Validation. Shekhar Chauhan: Writing - review \& editing. Deborah Anak Fo Ming: Data collection, data cleaning, data entry. Stephanie Fernandez A/P. Nelson Fernandez: Data collection, data cleaning, data entry. Colin Cornelius Pereira Johnson: Data collection, data cleaning, data entry. Agkesh Qumar A/L Thivakaran: Data collection, data cleaning, data entry. Mohammad Meshbahur Rahman: Conceptualization, Writingreview \& editing. Sonu Goel: Conceptualization.

\section{Declaration of competing interest}

The authors declare that they do not have conflict of interests.

\section{Acknowledgements}

Not Applicable.

\section{References}

1 Dawel A, Shou Y, Smithson M, et al. The effect of COVID-19 on mental health and wellbeing in a representative sample of Australian adults. Front Psychiatr. 2020;11. https://doi.org/10.3389/fpsyt.2020.579985.

2 Htay MNN, Marzo RR, AlRifai A, et al. Immediate impact of COVID-19 on mental health and its associated factors among healthcare workers: a global perspective across 31 countries. J Glob Health. 2020;10(2). https://doi.org/10.7189/ jogh.10.020381.

$3 \mathrm{Nu}$ Htay MN, Marzo RR, Bahari R, et al. How healthcare workers are coping with mental health challenges during COVID-19 pandemic? - a cross-sectional multicountries study. Clinical Epidemiology and Global Health. Published online May 7. 2021:100759. doi:10.1016/j.cegh.2021.100759.

4 Marzo RR, EQV III , Faller EM, Baldonado AM. Factors associated with psychological distress among Filipinos during coronavirus disease-19 pandemic crisis. Open Access Maced J Med Sci. 2020;8(T1):309-313. https://doi.org/10.3889/oamjms.2020.5146.

5 Marzo RR, Singh A, Mukti RF. A survey of psychological distress among Bangladeshi people during the COVID-19 pandemic. Clinical Epidemiology and Global Health. 2021; 10:100693. https://doi.org/10.1016/j.cegh.2020.100693.

6 Respati T, Irasanti SN, Sartika D, Akbar IB, Marzo RR. A nationwide survey of psychological distress among Indonesian residents during the COVID-19 pandemic. Int J Publ Health Sci. Published online 2021.

7 Choi EPH, Hui BPH, Wan EYF. Depression and anxiety in Hong Kong during COVID 19. Int J Environ Res Publ Health. 2020;17(10):3740.

8 González-Sanguino C, Ausín B, Castellanos MÁ, et al. Mental health consequences during the initial stage of the 2020 Coronavirus pandemic (COVID-19) in Spain. Brain Behav Immun. 2020;87:172-176.

9 Hyland P, Shevlin M, McBride O, et al. Anxiety and depression in the Republic of Ireland during the COVID-19 pandemic. Acta Psychiatr Scand. 2020;142(3):249-256.

10 Özdin S, Bayrak Özdin Ş. Levels and predictors of anxiety, depression and health anxiety during COVID-19 pandemic in Turkish society: the importance of gender. Int J Soc Psychiatr. 2020;66(5):504-511.

11 Wang C, Pan R, Wan X, et al. A longitudinal study on the mental health of general population during the COVID-19 epidemic in China. Brain Behav Immun. 2020;87: $40-48$.
12 Rampal L, Liew BS. Malaysia's third COVID-19 wave - a paradigm shift required. Med J Malaysia. 2021;76(1):1-4.

13 Elengoe A. COVID-19 outbreak in Malaysia. Osong Public Health Res Perspect. 2020;11 (3):93-100. https://doi.org/10.24171/j.phrp.2020.11.3.08.

14 Luo M, Guo L, Yu M, Jiang W, Wang H. The psychological and mental impact of coronavirus disease 2019 (COVID-19) on medical staff and general public - a systematic review and meta-analysis. Psychiatr Res. 2020;291:113190. https://doi. org/10.1016/j.psychres.2020.113190.

15 Kawohl W, Nordt C. COVID-19, unemployment, and suicide. The Lancet Psychiatry. 2020;7(5):389-390. https://doi.org/10.1016/S2215-0366(20)30141-3.

16 Irfan M, Shahudin F, Hooper VJ, Akram W, Ghani RBA. The psychological impact of coronavirus on university students and its socio-economic determinants in Malaysia. medRxiv. 2020. https://doi.org/10.1101/2020.10.27.20220723. Published online October 30, 2020, 10.27.20220723.

17 Sundarasen S, Chinna K, Kamaludin K, et al. Psychological impact of COVID-19 and lockdown among university students in Malaysia: implications and policy recommendations. Int J Environ Res Publ Health. 2020;17(17):6206. https://doi.org/ 10.3390/ijerph17176206.

$18 \mathrm{Al}$ Omari O, Al Sabei S, Al Rawajfah O, et al. Prevalence and predictors of depression, anxiety, and stress among youth at the time of COVID-19: an online cross-sectional multicountry study. Depression Research and Treatment. 2020. 2020, e8887727. https://doi.org/10.1155/2020/8887727.

19 Kroenke K, Spitzer RL, Williams JB, Kroenke K, Spitzer RL, Williams JB. The PHQ-9: validity of a brief depression severity measure. J Gen Intern Med. 2001;16(9): 606-613. Journal of General Internal Medicine. 2001;16(9):606-613.

20 Dunstan DA, Scott N. Norms for Zung's self-rating anxiety scale. BMC Psychiatr. 2020;20(1):90. https://doi.org/10.1186/s12888-019-2427-6.

21 Zung WW. A rating instrument for anxiety disorders. Psychosomatics: Journal of Consultation and Liaison Psychiatry. 1971;12(6):371-379. https://doi.org/10.1016/ S0033-3182(71)71479-0.

22 Gilbody S, Richards D, Brealey S, Hewitt C. Screening for depression in medical settings with the patient health questionnaire (phq): a diagnostic meta-analysis. J Gen Intern Med. 2007;22(11):1596-1602. https://doi.org/10.1007/s11606-0070333-y.

23 Urtasun M, Daray FM, Teti GL, et al. Validation and calibration of the patient health questionnaire (PHQ-9) in Argentina. BMC Psychiatr. 2019;19(1):291. https://doi. org/10.1186/s12888-019-2262-9.

24 Islam MA, Barna SD, Raihan H, Khan MNA, Hossain MT. Depression and anxiety among university students during the COVID-19 pandemic in Bangladesh: a webbased cross-sectional survey. PloS One. 2020;15(8), e0238162. https://doi.org/ 10.1371/journal.pone.0238162.

25 Kamberi F, Jaho J, Mechili EA, Sinaj E, Skendo H. Effect of Covid-19 pandemic on mental health among Albanian people residing in the country and abroad implications for mental care. Arch Psychiatr Nurs. 2020;34(6):507-512. https://doi. org/10.1016/j.apnu.2020.08.003.

26 Dunstan DA, Scott N, Todd AK. Screening for anxiety and depression: reassessing the utility of the Zung scales. BMC Psychiatr. 2017;17(1):329. https://doi.org/10.1186/ s12888-017-1489-6.

27 Xiong J, Lipsitz O, Nasri F, et al. Impact of COVID-19 pandemic on mental health in the general population: a systematic review. J Affect Disord. 2020;277:55-64. https://doi.org/10.1016/j.jad.2020.08.001.

28 Veldhuis CB, Nesoff ED, McKowen ALW, et al. Addressing the critical need for longterm mental health data during the COVID-19 pandemic: changes in mental health from April to September 2020. Prev Med. 2021;146:106465. https://doi.org/ 10.1016/j.ypmed.2021.106465.

29 Brooks SK, Webster RK, Smith LE, et al. The psychological impact of quarantine and how to reduce it: rapid review of the evidence. Lancet. 2020;395(10227):912-920. https://doi.org/10.1016/S0140-6736(20)30460-8.

30 Bäuerle A, Teufel M, Musche V, et al. Increased generalized anxiety, depression and distress during the COVID-19 pandemic: a cross-sectional study in Germany. Journal of Public Health. 2020;42(4):672-678. https://doi.org/10.1093/pubmed/fdaa106.

31 Shah SMA, Mohammad D, Qureshi MFH, Abbas MZ, Aleem S. Prevalence, psychological responses and associated correlates of depression, anxiety and stress in a global population, during the coronavirus disease (COVID-19) pandemic. Community Ment Health J. 2021;57(1):101-110. https://doi.org/10.1007/s10597020-00728-y.

32 Vindegaard N, Benros ME. COVID-19 pandemic and mental health consequences: systematic review of the current evidence. Brain Behav Immun. 2020;89:531-542. https://doi.org/10.1016/j.bbi.2020.05.048.

33 Cabarkapa S, Nadjidai SE, Murgier J, Ng CH. The psychological impact of COVID-19 and other viral epidemics on frontline healthcare workers and ways to address it: a rapid systematic review. Brain, Behavior, \& Immunity - Health. 2020;8:100144. https://doi.org/10.1016/j.bbih.2020.100144.

34 Bradbury-Jones C, Isham L. The Pandemic Paradox: The Consequences of COVID-19 on Domestic Violence. Wiley Online Library; 2020.

35 Ghoshal R. Twin public health emergencies: covid-19 and domestic violence. Indian J Med Ethics. 2020;5:1-5.

36 Hsu L-C, Henke A. COVID-19, staying at home, and domestic violence. Rev Econ Househ. 2021;19(1):145-155.

37 Sharma A, Borah SB. Covid-19 and domestic violence: an indirect path to social and economic crisis. Journal of family violence. Published online. 2020:1-7.

38 Neil J. Domestic violence and COVID-19: our hidden epidemic. Australian journal of general practice. 2020;49.

39 Krogh J, Hjorthøj C, Speyer H, Gluud C, Nordentoft M. Exercise for patients with major depression: a systematic review with meta-analysis and trial sequential 
analysis. BMJ Open. 2017;7(9), e014820. https://doi.org/10.1136/bmjopen-2016014820.

40 Stonerock GL, Hoffman BM, Smith PJ, Blumenthal JA. Exercise as treatment for anxiety: systematic review and analysis. Annals of behavioral medicine. 2015;49(4): 542-556.

41 Firth J, Rosenbaum S, Stubbs B, Gorczynski P, Yung AR, Vancampfort D. Motivating factors and barriers towards exercise in severe mental illness: a systematic review and meta-analysis. Psychol Med. 2016;46(14):2869-2881.

42 Staiano AE, Marker AM, Martin CK, Katzmarzyk PT. Physical activity, mental health, and weight gain in a longitudinal observational cohort of nonobese young adults. Obesity. 2016;24(9):1969-1975.
43 Bellón JA, Conejo-Cerón S, Sánchez-Calderón A, et al. Effectiveness of exercise-based interventions in reducing depressive symptoms in people without clinical depression: systematic review and meta-analysis of randomised controlled trials. Br J Psychiatr. 2021:1-10. Published online.

44 Hossain MM, Tasnim S, Sultana A, et al. Epidemiology of mental health problems in COVID-19: a review. F1000Research. 2020;9.

45 Giorgi G, Lecca LI, Alessio F, et al. COVID-19-related mental health effects in the workplace: a narrative review. Int J Environ Res Publ Health. 2020;17(21):7857. 